JALADRI (Vol. 6.2) (2020)

Jurnal Pendidikan Bahasa dan Sastra Daerah

http://jurnal.upmk.ac.id/index.php/jaladri/

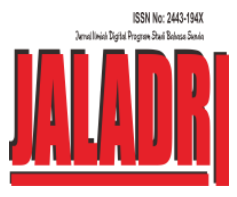

\title{
ANALISIS STRUKTUR MANTRA DALAM TRADISI NGUJUBAN TANGGAL DI DESA SUKAJAYA KECAMATAN CIMAHI KABUPATEN KUNINGAN
}

\section{Padli1), Heti Triwahyuni2)}

email: padli@gmail.com1), triwahyuniheti@upmk.ac.id2)

Pendidikan Bahasa dan Sastra Daerah

STKIP Muhammadiyah Kuningan

\begin{tabular}{l}
\hline Info Artikel \\
Sejarah Artikel: \\
Diterima 10 Agustus 2020 \\
Disetujui 10 Oktober 2020 \\
Dipublikasikan 25 Oktober 2020 \\
\end{tabular}

Kata Kunci:

Analisis Struktur, Mantra, Tradisi Ngujuban Tanggal

\begin{abstract}
Abstrak
Penelitian ini bertujuan untuk melestarikan kebudayaan orang Sunda kususnya dalam bidang kesastraan adanya peninggalan suatu karya sastra, manusia Sunda pada zaman dahulu, yang sekarang keberadaannya hampir punah, seperti karya sastra mantra dalam tradisi ngujuban tanggal di Desa Sukajaya Kecamatan Cimahi Kabupaten Kuningan. Dengan diadakan penelitian ini, supaya tradisi ini akan terus turun temurun berjalan, dan tetap ada di tengah berjalannya perkembangan zaman modern ini. Sebagai generasi muda yang mengerti akan pentingnya suatu identitas bangsa yaitu adanya budaya, yang di wariskan dari nenek moyang kita, seperti adanya mantra dina tradisi ngujuban tanggal. Sejaraha tradisi ngujuban tanggal di desa sukajaya: Adapun hasil penelitian yang dilakukan di Desa Sukajaya Kecamatan Cimahi Kabupaten Kuningan dengan mengunakan wawancara kepada narasumber ditemukan mantra-mantra yang lain juga selain mantra ngujuban tanggal yaitu mantra jangjawokan tebar binih, mantra jangjawokan babut binih, mantra jangjawokan tandur dan mantra rajah panen pare. Kesimpulannya mantra yang di temukan ada 5 mantra 2 mantra rajah 3 mantra jangjawokan. Mantra-mantra ini besar manfaatna kususnya untuk masarakan Desa Sukajaya Bahwa di Desa Sukajaya Ada Peninggalan kebudayaan orang sunda kususnya dina bidang sastra, yaitu bisa buat bahan pengetahuan bagi orang banyak.
\end{abstract}


Key Words:

Structure Analysis, Mantra, Ngujuban Date Tradition
This study aims to preserve the culture of the Sundanese people, especially in the field of literature, there is a legacy of a literary work, Sundanese people in ancient times, which are now almost extinct, such as the literary work of mantras in the tradition of ngujuban dates in Sukajaya Village, Cimahi District, Kuningan Regency. By conducting this research, so that this tradition will continue from generation to generation, and continue to exist in the midst of the development of this modern era. As a young generation who understand the importance of a national identity, namely the existence of culture, which is inherited from our ancestors, such as the mantra in the tradition of ngujuban dates. The history of the tradition of ngujuban dates in Sukajaya village: The results of research conducted in Sukajaya Village, Cimahi District, Kuningan Regency by using interviews with informants found other spells besides the ngujuban date mantra, namely the jangjawokan spell tebar binih, jangjawokan babut binih mantra, jangjawokan tandur mantra and the harvest spell of bitter melon. In conclusion, the spells found were 5 spells, 2 rajah spells, 3 jangjawokan spells. These mantras are very useful, especially for the people of Sukajaya Village. That in Sukajaya Village there is a cultural heritage of the Sundanese people, especially in the field of literature, which can be used as material for knowledge for many people. 


\section{PENDAHULUAN}

Kabudayaan merupakan identitas suatu bangsa yang secara turun temurun yang diwariskan oleh nenek moyang dari zaman dulu samapai zaman sekarang. Serta dalam satra kabudayaan yang mencakup banyak dalam bidang ilmu pengetahuan, kepercayaan, seni, moral, adat istiadat, serta kebiasaan-kebiasaan yang di dapatkan dari manusia sebagai anggota masarakat. menurut sajarahna ngujuban tanggal di Jaman dulu sabagai keparcayaan dan keyakinan di Zaman Hindu-Budha, di Zaman sekarang yang tadinya kepercayaan sarta kayakinan, sudah rubah fungsinya menjadi tradisi kebudayaan serta untuk tambahan ilmu pengetahuan dalam bidang sastra. Dalam kehidupan sehari-hari adanya perkembangan kesusastraan Sunda melalui lisan cara cerita dimasarakat dan adanya komunikasi antara manusia dan manusia yang lainnya melalui bahasa sebab salah satu alat sastra melalui Bahasa.

Basa merupakan alat komunikasi manusia dalam kehidupan sehari-hari di lingkungan masyarakat. adanya Basa, manusia bisa ngungkapkeun rasa, pikiran, dan keinginan dalam kehidupannya. melalui Basa, manusia bisa menciptakan karya sastra. Karya sastra adalah karya seni yang digunakan melalui Basa, salahsatunya adalah puisi. Menurut pendapat Iskandarwassid, "Puisi adalah keterampilan Bahasa karangan yang aturannya yang penuh dengan Rima tersebut wangunnya dan diksinya, lain dalam tengah kalimat cara basa sehari- hari atau cara dalam bentuk prosa. Karya sastra Sunda bisa dibagi-bagi jadi dua yaitu puisi Zaman dulu dan puisi modérn. Dalam puisi Sunda Zaman dulu salahsatunya adanya mantra. Mantra adalah termasuk puisi Zaman dulu yang tidak berbentuk cerita (naratif) serta perkembangannya secara lisan. Dalam kehidupan sehari-hari masarakat Zaman dahulu mantra dekat dengan kehidupan keagama serta kepercayaan masyarakatnya. Mantra berupa do'a husus yang disampaikan melalui basa serta punya maksud yang tertentu. Mantra dapat mempunyai kekuatan gaib dalam menyampaikannya melalui ritual husus. Menggunakan mantra teu sembarangan, tapi aya padikana atau aturanana. Tujuan memakai mantra rupa-rupa.teras manusia yang menggunakan mantra harus menuruti sarat yang sudah ditengtukan yang dianggap menguasai mantra. Mantra agar terus ada dan berkembang, atau bisa juga leungit, nyambung dengan kehidupan manusia cara memakainya. Masyarakat yang menggunakan mantra tujuan untuk magis sekarang sudah tidak rame lagi. serta yang mempunyai hanya golongan orangtua saja, dan bagi yang muda sangat tidak ada. baiknya mantra merupakan bagian dari budaya dan sastra daérah yang perlu diperhatikan dan disebarluaskan, sebab ini adalah salah satu peninggalan budaya dari Zaman dahulu yang besar nilainya. Salah satu usaha untuk menyebar luaskan budaya daerah yang berbentuk berupa sastra lisan yaitu diadakanbya penelitian. Dengan adanya penelitian, sastra lisan kudu didokuméntasikan dalam bentuk tulisan serta bisa dianalisis sampai dengan bisa di ketahui struktur bentukna.Sesudah didokuméntasikan serta dianalisis struktur bentukna.

\section{METODE PENELITIAN}

Penelitian ini dilakukan di Desa Sukajaya Kecamatan Cimahi Kabupaten Kuningan. Yaitu tentang analisis struktur mantra dina tradisi ngujuban tanggal yang berada di Desa Sukajaya Kecamatan Cimahi Kabupaten Kuningan, yang berdasarkan pada fungsi dan penelitian ini mencakup; Isi, Basa, Purwakati, Dan bentuk Wirahma. Sesudah dianalisis struktur bentukna puisi mantra seterusnya dijadikan untuk tambahan kesusastraan Sunda Zaman dulu Serta untuk ilmu pengetahuan masarakat setempat. Letak geografis Desa Sukajaya ka kabupaten kurang lebih 25 kilometer, Desa Sukajaya Desa yang paling ujung diantara Desa Cikeusal dan Desa Mulyajaya. Di sebelah timur di bates ku hutan Sukajaya, di sebelah selatan di bates ku Kecamatan Cimahi dan Desa Kananga, dan jumlah penduduk Desa Sukajaya Kurang Lebih aya 35500 jiwa, laki-laki dan perempuan. Mata pencaharian masarakat Desa Sukajaya paling banyak bercocok tanam atau petani, serta ada beberapa yang jadi guru,Bengkel,supir,dagang dan kuli bangunan.

Métode penelitian yang sudah digunakan oleh paneliti adalah métode kualitatif. Menurut dalam Arikunto menyebutkan:

"Penelitian kualitatif adalah tampilan yang berupa kata-kata lisan atau tertulis yang dicermati oleh peneliti, dan benda-benda yang diamati sampai 
detainya agar dapat ditangkap makna yang tersirat dalam dokumen atau bendanya".

Sama dengan pendapat di atasa peneliti harus melakukan penelitian karya sastra lisan atau tulisan yang berkembang di masyarakat Desa Sukajaya Kecamatan Cimahi Kabupaten Kuningan, serta intinya bentukbidang karya sastra Zaman dulu. Selain itu penelitian harus bisa menggunakan pendékatan déskriptif analitik. Hal ini sama dengan pendapat Margono yang menyampaikan, "Dalam penelitian déskriptif analitik data yang didapatkan ( kata-kata, gambar, tingkah laku) lain berupa bilangan atau angka statistik, tapi tetap dalam bentuk kualitatif yang mempunya harti lebih dalam dibandingkan angka atau frékunési"

Teknik penelitian, suyatna menyebutkan, "Téhnik teknik penelitian merupakan salah satu usaha bagaimana cara (prosedur) yang bisa diandalkan dengan menggunakan métode tertentu, supaya tujuan dan sasaran yang di inginkan dalam suatu penelitian yang bisa tercapai". Sedangkan menurut Uhar Suharsaputra menegaskan, "Tehnik penelitian merupakan langkah-langkah dalam menentukan menadapatkan data yang seterusnya bakal diolah berdasarkan keperluan data tersebut untuk mendapatkan hasil yang di inginkan dari objek penelitian.

\section{Teknik penelitian}

Teknik yang digunakan oleh peneliti adalah teknik observasi, wawancara, telaah pustaka dan dokumentasi. Seperti yang dijelaskan dibawah ini:

\section{a. Observasi}

Téhnik observasi adalah dalam penelitian yang teliti secara langsung pada objék yang harus di teliti dari kedekatan serta nilik serta melihat keadaan perkembanganya dilapangan. Dalam kegiatan ini, peneliti melibatkan diri secara langsung (aktif partisipasif) dalam semua keadaan yang ada hubungannya kepada peneliti. Téhnik ini juga langkah yang paling utama untuk mendapatakan semua data yang di perlukan oleh peneliti.

\section{b. Wawancara}

Menurut Basrowi dan Suwandi, "Wawancara adalah dialog yang mempunyai tujuan antara dua pihak, yaitu yang mewancarai yang harus menanyakan sarta yang diwawancara yang harus menjawab". Téhnik ini digunakan untuk melakukan komunikasi dengan narasumber secara langsung yang bertujuan untuk mendapatkan data atau tambahan bahan penelitian yang lainnya.

\section{c. Talaah Pustaka}

Talaah pustaka adalah salahsatu téhnik yang digunakan untuk mengumpulakan data yang di teliti secara detail, isi buku atau téori-téori para ahli yang ada kaitannya dengan penelitiselain itu peneliti bisa memberikan pendapat atau menyimpulkan dari semua para ahli. Hal ini sependapat dengan pendpat Isnéndés yén, "Telaah pustaka selain digunakan untuk mencari data, bisa juga untuk menentukan dasar-dasar téoritis yang ada kaitannya dengan subjék penelitian yang sedang diteliti.

\section{d. Dokuméntasi}

Menurut dalam Kamus Sunda Indonésia Online, "Dokuméntasi asal katanya dari dokumén yang artinya merekam suara, gambar dalam film untuk dijadikan bukti keterangan". Sedangkan menurut Arikunto yén, "Dalam penelitian harus memperhatikan tiga sumber yang bisa menguatkan informasi adalah tulisan (paper), tempat (place), dan manusia (people)".

Dalam melaksanakan penelitian, peneliti harus bisa mendokumentasikan data atau bahan-bahan anu yang ada kaitannya dengan peneliti, adapun berupa barang, tulisan, rékaman dan gambar atau poto tinarasumber.

\section{Téhnik Ngolah Data}

Langkah-langkah yang harsu dilakukan oleh peneliti dalam melakukan penelitian meliputi:

a. Menentukan mantra yang akan dianalisis,

b. Mengelompokan jenis-jenis mantra dalam bentuk tradisi ngujuban tanggal yang lainnya kedalam jenis-jenisnya.

c. menganalisis berdasarkan unsur bentukna (isi mantra, bahasa dalam mantra, purwakanti, bentuk dan wirahma). 


\section{Dokumentasi Gambar}

1. Peneliti Dan Narasumber Naskah Mantra Rajah Dan Mantra Jangjawokan tebar binih, babut binih, tandur.

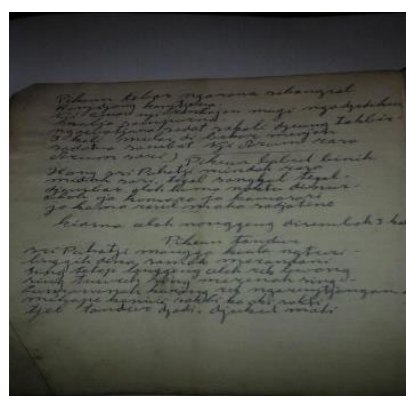

X
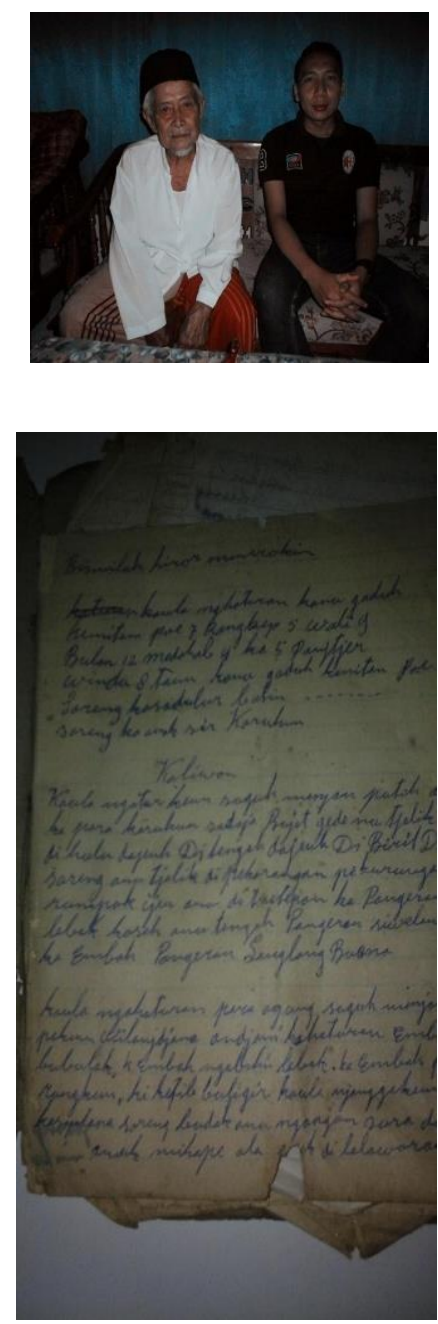

\section{HASIL DAN PEMBAHASAN}

\section{Conto Stuktur Mantra Ngujuban Tanggal}

Mantra Ngujuban Tanggal
Bismillahirrohmanirrohim

Kaula ngahaturkeun suguh alus

Kanu gaduh kamitan poe tujuh

Rangkep lima wali salapan

Bulan dua belas medahal papat kalima pancer

Windu dalapan taun kanu gaduh kamitan poe jum'ah

Sareng kasadulur batin sukmarum

Sukma dabaniah manda kidul

Sukma dawilayah manda kulon

Sukma sajati manda kaler

Sukma bundel mani putih manda tengah wujudna abdi

\section{Fungsi Mantra Rajah Ngujuban Tanggal}

Fungsi Mantra Ngujuban Nyaitu untuk meminta keselamatan, supaya tidak terjadi hal-hal yang tidak diingikan. dari hasil analisis, mantra ngujuban tanggal, mantra ngujuban tanggal adalah termasuk mantra jenis mantra Rajah, selain mantra rajah adapula mantra yang lain yang didapatakan yaitu jenis mantra jangjawokan yang fungsina untuk meminta keselametan dalam melakukan hiji pekerjaan.

Contoh : Mantra Tebar Binih, Mantra Babut Binih, Mantra Tandur, Sareng mantra Rajah panen pare.

\section{a. Isi Mantra Rajah Ngujuban Tanggal}

Dari hasil analisis, mantra ngujuban tanggal ini, untuk meminta keselamatan. Cara memkainya adalah membacakan mantra ngujuban tanggal di dalam waktu atau hari yang sudah ditentukan

Isi basa yang ada dalam mantra ngujuban tanggal. sadulur batin sukma rum,sadulur urang anu teu bisa katenjo ku panon supartos roh/jiwa. Ka anasir, anu hartina opat unsur nyaeta angin, bumi, seneu, jeung cai,sukma dabaniah manda kidul, roh anu nguasaan dibelah kidul, sukma dawilayah manda kulon, roh anu nguasaan diwilayah kulon, 
sukma sajati manda kaler, roh anu aya di belah kaler, sukma bundel mani putih manda tengah,sukma anu aya di tengahtengah.

Berdasarkan hasil penelitian bisa disimpulkan, mantra ngujuban tanggal ini untuk memita keselamatan kepada para leluhur, meminta kaberkahanna supaya tidak ada hal-hal yang tidak diinginkan.

b. Basa dina Mantra Rajah Ngujuban Tanggal

Basa anu digunakanpaling banyak dalam Mantra Ngujuban Tanggal Basa Sunda dina perkembangan jaman kapangaruhan ku Basa Arab. Contona: Tina Basa Sunda jeung kapangaruhan ku Basa Arab, Bismillahirrohmanirrohim, Asalamualaikum, kaula ngahaturkeun, suguh alus menyan bodas, kanu gaduh kamitan poè tujuh jsb.

c. Wangun Jeung Wirahma dina Mantra Rajah Ngujuban Tanggal

Mantra ngujuban tanggal diwangun $\mathrm{ku} 14$ padalisan. Jumlah engang dina unggal padalisan paling lobana 18 engang, teras aya hiji nu paling letikna aya 8 engang. Salian kitu, jumlah randegan dina saban padalisan lolobana 2 randegan tur aya 2 padalisan anu jumlahna 3 randegan padalisan kahiji jeung kadua.

d. Purwakanti Rajah dina ngujuban tanggal

purwakanti anu nyangkaruk dina mantra ngujuban tanggal; pangluyu 1, mindoan kawit 1, larasmadiya 1. San

\section{KESIMPULAN}

Mantra yang ditemukan di Desa Sukajaya Kecamatan Cimahi ada 5 mantra yaitu, mantra ngujuban tanggal, mantra tebar binih, mantra babut binih, mantra tandur, mantra panen pare, tina 5 mantra anu kapanggih, anu dianalisis anu pang lobana tina padalisanna nya eta mantra panen pare aya 61 padalisan, anu dianalisis dumasar kana struktur pangwanguna. Sabada dianalisis bisa dirumuskeun kacindekan saperti:

1. Mantra anu kakumpulkeun di Désa Suakajaya, Kacamatan Cimahi jumlahna 5 mantra. Mantra ieu meunang ti sa urang narasumber anu mangrupa tokoh masarakat Bapa Taryana, mantra anu kapanggih aya 2 wangun mantra nya eta, ngawengku; 2 Rajah, 3 Jangjawokan.

2. Mantra anu kapanggih 4 anu dianalisis struktur pangwangunna, anu ngawengku; eusi, basa, purwakanti, wangun jeung wirahma. Eusi mantra anu dianalisis lolobana ngabogaan tujuan keur kahadéan menta kasalametan dina ngalakukeun hiji pagawean, saperti; Mantra ngujuban tanggal jeung mantra pare nya eta fungsina, menta kasalametan jeung barokah supartos henteu aya hal-hal anu teu dipikahyang, mantra tebar binih, mantra babut binih, mantra tandur, nyaeta fungsina menta kasalametan upama erek ngamimitian hiji pagawean. Sarta asal muasal mantra turun temurun ka Bapa Taryana ti Bapa Yanto, nikah ka pun lanceukna Bapa Taryana, adapun. Mantra ngujuban tanggal di Desa Sukajaya Kecamatan Cimahi. Ngagunakeun Basa, dina mantra lolobana ngagunakeun Basa Sunda. Sanajan aya ogé sababraha mantra anu kacampuran ku basa séjén, saperti; basa Arab, basa Jawa, jeung basa wewengkon Cirebon. Mantra anu dianalisis diwangun $\mathrm{ku} 14$ padalisan mantra ngujuban tanggal, mantra tebar binih 3 padalisan, mantra babut binih 6 padalisan, mantra tandur 9 padalisan. Sarta wirahma mantra dina unggal padalisan henteu tangtu atawa béda-béda jumlahna. Tapi, lolobana mantra diwangun ku 9 engang jeung 2 randegan. Sedengkeun purwakanti anu mindeng kapanggih dina unggal mantra nya éta purwakanti mindoan kawit jeung mindoan kecap (purwakanti mindoan kawit nya eta anu timbul lantaran aya kecap anu dipindo teras purwakanti mindoan kecap nya eta malikan kecap dina kalimah tapi hartina béda).

\section{REFERENSI}

Iskandarwassid. 2003. Kamus Istilah Sastra: Pangdeudeul Pangajaran Sastra Sunda. Bandung: CV. Geger Sunten 
Tamsyah, B. (1996). Pangajaran SastraSunda:Waluyo. 1995. Teori dan Apresiasi Puisi. Jakarta: PikeunSiswa SD, SLTP, SMU, jeungUmum. Erlangga

Bandung: CV. PustakaSetia.

http://ixe-11.blogspot.co.id/2012/07/definisi-

dan-pengertian-

tradisi.html\#ixzz3mOHLxhBV

Rusyana. (1970). Bagbagan Puisi Mantra Sunda. Bandung: Proyek Penelitian Pantun \& Folklore Sunda

Retty Isnendes (2008:1)

Retty Isnendes (2008:6)

Koswara. (2001). Racikan Sastra:Pangdeudeul Perkkuliahan Sastra Sunda. Bandung: JPBD FPBS UPI

Pradopo (2010). Pengkajian Puisi. Yogyakarta: Gadjah Mada University Press

Isnendes,R.(1998).Analisis Puisi Mantra di Kacamatan Nagrak Kabupatén Sukabumi. SkripsiSarjanapada JPBD FPBS UPI Bandung: tidakditerbitkan.

Iskandarwassid. (2003). Kamus Istilah Sastra: Pangdeudeul Pangajaran Sastra Sunda. Bandung: CV. Geger Sunten

Rusyana. (1970). Bagbagan Puisi Mantra Sunda. Bandung: Proyek Penelitian Pantun \& Folklore Sunda

M.A. Salmun. (1963). Kandaga Kasusastraan Sunda. Bandung: Ganaco

Arikunto, 2010. Prosedur Penelitian Suatu Pendekatan Praktik. Yogyakarta. Rineka Cipta

Sugiono. 2009. "Metode Penelitian Kuanitatif, Kualitatif dan $R \& B$ ". ALFABETA, Bandung

Suyatna. 2002. Pengantar Metodologi Penelitian Pendidikan dan Pengajaran Bahasa. Bandung: Departemen Pendidikan Nasional UPI

Suyatna. 2002. Pengantar Metodologi Penelitian Pendidikan dan Pengajaran Bahasa. Bandung: Departemen Pendidikan Nasional UPI

UharSuharsaputra. 2011. MetodePenelitian. Kuningan, Rumah Buku Press

Basrowi jeung Suwandi. 2011. Memahami Penelitian Kualitatif. Jakarta: PT. Rineka Cipta

Isnendes. 1998). Analisis Puisi Mantra di Kacamatan Nagrak Kabupatén Sukabumi. Skripsi Sarjana pada JPBD FPBS UPI Bandung

Kamus Sunda Indonesia Online

Arikunto. 2010. Prosedur Penelitian: Suatu Pendekatan Praktik. Jakarta: PT. Rineka Cipta

Siswantoro. 2011. Metode Penelitian Sastra: Analisis Struktur Puisi. Yogyakarta: Pustaka Pelajar

Iskandarwassid. 2003. Kamus Istilah Sastra: Pangdeudeul Pangajaran Sastra Sunda. Bandung: CV. Geger Sunten 